(first broods only) 950; Eastern Bluebird (first broods) 160; Crossbred Bluebirds 3; Tree Swallow 2,550; House Sparrow 400; House Wren 40; deer mouse 100; red squirrel 10; Starling 5.

\section{INDIAN HEAD BLUEBIRD TRAIL REPORT — 1974}

\section{by LORNE SCOTT*}

After a long drawn-out winter with a record amount of snowfall, spring finally arrived in mid-April. The peak migration of Mountain Bluebirds was about 2 weeks later than usual and consequently nesting didn't begin until mid-May.

On May 18 a 5-day rain began and temperatures remained in the $40^{\circ} \mathrm{F}$ range. This prolonged wet and cold spell caused many of the female Mountain Bluebirds to abandon their nests in order to find enough food to stay alive.

When the weather finally did clear and become warmer, the bluebirds returned to the nest boxes. Some of the females began incubating the cold eggs but in most cases only two or three hatched from the clutch of six. Many of the bluebirds simply built another nest over the cold wet eggs and laid a new clutch.

Despite the poor start early in the nesting season, a record number of Mountain Bluebirds was raised in the nest boxes. One hundred female bluebirds were captured and banded while incubating eggs. Another 30 females which were caught were already wearing bands from the previous 4 years. Two of these females had been banded as adults in 1970, which means they are at least 5 years old, a ripe old age for a wild bird of

*Box 995 ,

Indian Head, Saskatchewan.

SOG $2 \mathrm{KO}$. this size. None of the bluebirds banded in 1969 were caught this year. A total of 800 young bluebirds were banded between May 28 and August 11 .

Tree Swallows also had another successful nesting season. Some 200 females and 1,600 young were banded. However, the success of Tree Swallows would be nearly doubled if House Sparrows could be eliminated along the trail.

One of the highlights this year was having a partial albino female Mountain Bluebird nesting. Her beak was white instead of black and the feathers on her head and back of her neck were pure white rather than the normal blue-grey colour.

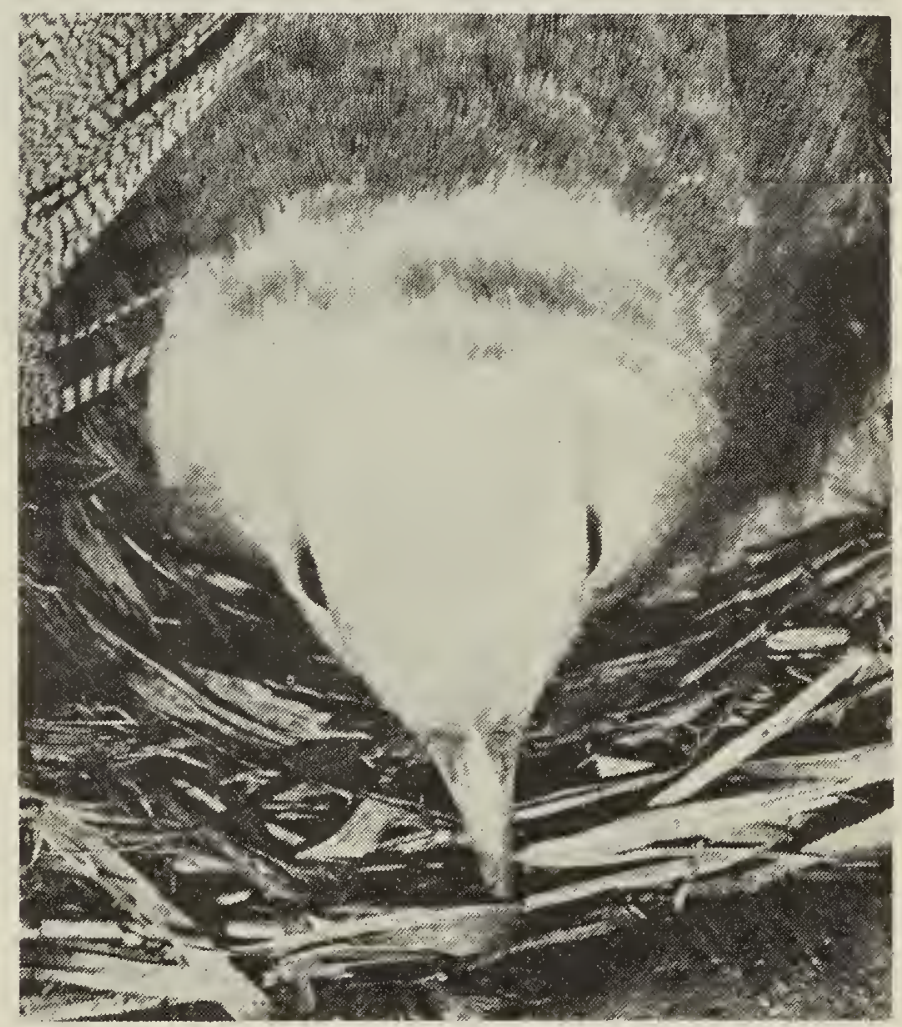

Lorne Scott

Partial albino female Mountain Bluebird at Indian Head, Saskatchewan. May 26, 1974.

Another first for this year was having a pair of Tree Swallows hatch and raise a Mountain Bluebird. Each year two or three bluebird nests are taken over by swallows while the bluebirds are laying eggs. The Tree Swallows lay their eggs in the nest containing one or more bluebird eggs. Usually the bluebird eggs hatch along with those of the swallows. However, 


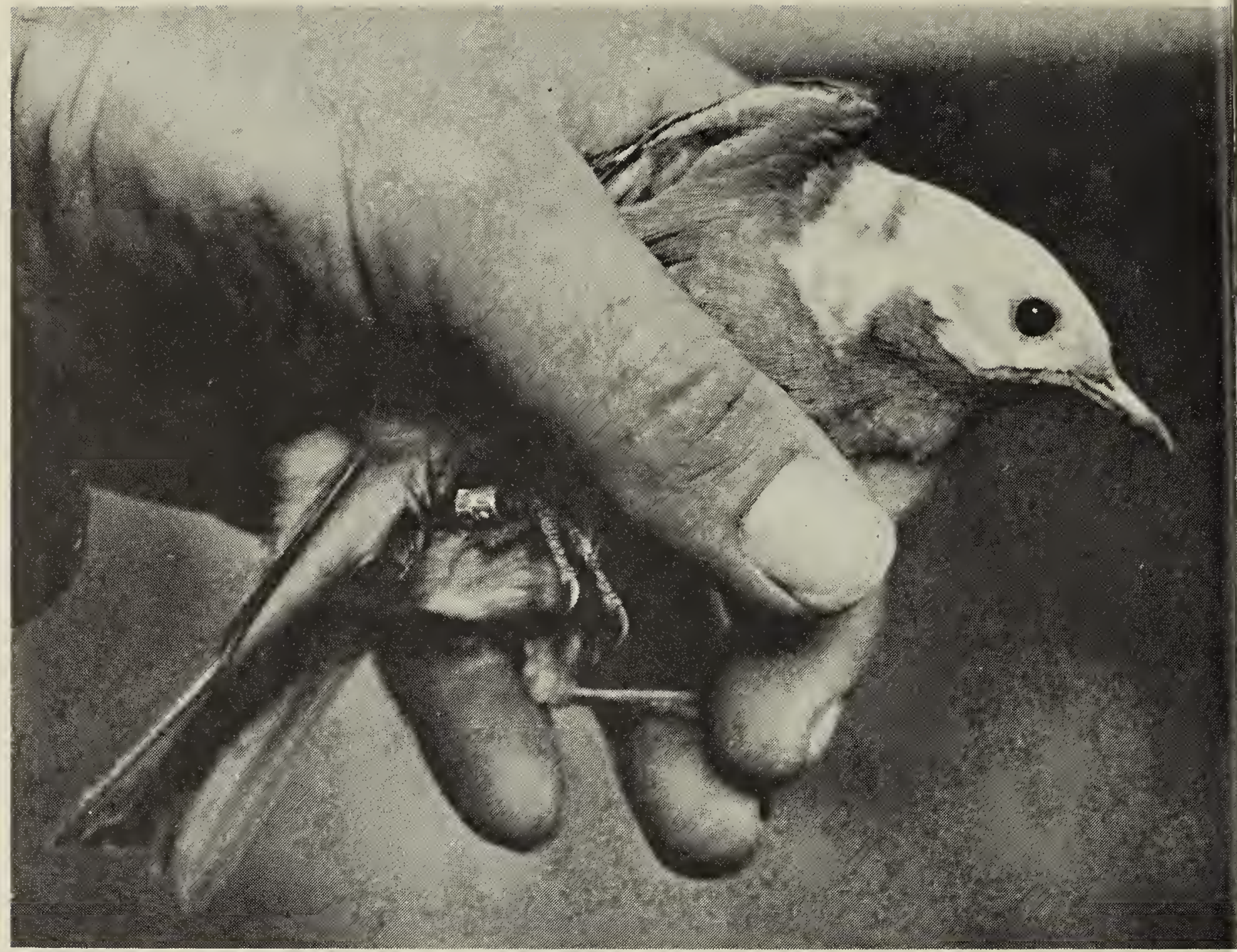

Lorne Scott White-headed female Mountain Bluebird, Indian Head, Saskatchewan. May 26, 1974.

the young bluebirds have always died in the nest until this year when one young bluebird was fledged along with five Tree Swallows.

Since 1963, 1,800 nest boxes have been set out along the Indian Head bluebird trail. A total of 4,000 bluebirds and 8,000 Tree Swallows have been banded since 1969. Several hundred more bluebirds and swallows that were not banded have been fledged from the houses.

I hope to set out another 200 houses next spring but due to the time and expense involved I do not expect to carry out an extensive banding program as I have done in the past.

\section{SASKATOON BLUEBIRD TRAIL - 1974}

by DONALD S. HOUSTON*

This year, our success with the bluebird house trail was again good. We relocated a number of boxes that had been used by House Sparrows, into proven bluebird territory, and added a few more (including seven contributed by Leo Smith of Toronto) to bring the total in our main study area to 233 houses. Of these, eight were damaged and empty and only seven were intact and unoccupied - for a 94\% occupancy rate.

We had 54 nestboxes used by Moun-

*863 University Drive,

Saskatoon, Saskatchewan.

S7N 0J8. 